\title{
Contact With the Workplace During Long-Term Sickness Absence and Worker Expectations of Return to Work
}

\author{
John Selander, ${ }^{1}$ Åsa Tjulin, ${ }^{2,3,4}$ Ulrika Müssener, ${ }^{5}$ and Kerstin Ekberg ${ }^{3,4}$ \\ ${ }^{1}$ Centre for Rehabilitation Research, Department of Health Sciences, Mid Sweden University, Ostersund, Sweden, \\ ${ }^{2}$ Division of Public Health Sciences, School of Health, Care and Social Welfare, Mälardalens University, Sweden, \\ ${ }^{3}$ National Centre for Work and Rehabilitation, Department of Medical and Health Sciences, Linkoping University, Sweden, \\ ${ }^{4}$ HELIX Vinn Excellence Centre, Linkoping University, Sweden \\ ${ }^{5}$ Division of Community Medicine, Department of Medical and Health Sciences, Linkoping University, Sweden
}

\begin{abstract}
S ince long-term sickness absence constitutes a problem in most western countries, research that can facilitate return to work (RTW) is important. Today there is evidence that the social context at the workplace has a significant impact on return to work. The dual aims of the study was firstly to investigate the pattern and quality of contact between employees on long-term sick leave and different actors at the workplace, and secondly to investigate whether contacts with the workplace were associated with expectations regarding return to work. An explorative method and descriptive design was used for the first aim. For the second aim, the data was analysed in a multivariate logistic regression model. The results show that employees had frequent and, in most cases, appreciated contact with their supervisor and co-workers. Contact with other workplace actors; that is, the occupational health unit, the union representative, and the human resources department, were less frequent. Employees who experienced the contact as supportive and constructive were far more positive and optimistic than others regarding return to work. It is concluded that supervisors and co-workers should be aware that they play a significant role in the return-to-work process, and that quality of contact is what matters.
\end{abstract}

Keywords: co-worker, long-term sickness, return to work, workplace contact

Long-term sickness absence constitutes a problem in most western countries, and Sweden is no exception. Long-term sickness absence has consequences at different levels. At a societal level, it leads to increased costs for the health care and social insurance systems (Young et al., 2005); at a company level, it leads to increased costs and loss of production (Ekman, Jonhagen, Hunsche, \& Jonsson, 2005); and for individuals, it has negative financial consequences, decreased wellbeing and less participation in everyday life (Waddell \& Burton, 2006). Against this background, research that can facilitate return to work (RTW) is important.

Historically, RTW research has primarily focused on the medical and psychological aspects of injury and illness, while research on more social aspects has been less common. Recent studies (Tjulin, 2010) show that the social context, especially at the workplace, also has a significant impact on the RTW process. Conditions such as early workplace contact with the injured worker, communication between stakeholders, different kinds of social support and a climate of goodwill at the workplace are factors that facilitate RTW (Baril, Clarke, Friesen, Stock, \& Cole, 2003; Franche et al., 2005; MacEachen et al., 2006; Reynolds, Wagner, \& Harder, 2006; Lysaght \& Larmour-Trode, 2008; Young, 2010; Hepburn, Franche, \& Francis, 2010; Kosny et al. 2013; Lysaght, Fabrigar, Larmour-Trode, Stewart, \& Friesen, 2012). Some studies (Tjulin, MacEachen, \& Ekberg, 2010, 2011) also show that workplace social interaction, especially between the re-entering worker and his/her supervisor and co-workers, plays a significant role during the RTW process. Given this background, it is of interest to further investigate the pattern and quality of contact between employees on long-term sick leave

Address for correspondence: John Selander, Department of Health Sciences, Mid Sweden University, Ostersund, Sweden. E-mail: john.sedlander@miun.se 
and potential supportive actors at the workplace. Since recent studies show that the injured or sick worker's own expectations regarding RTW have a strong predictive value for actual RTW (Holmgren, Dahlin, \& Ivanoff, 2004; Hou et al., 2012; Lötters \& Burdorf, 2006; Nieuwenhuijsen, Verbeek, de Boer, Blonk, \& van Dijk, 2006; Planan, Lopez, Martinez, Delclos, \& Benavides, 2012; Shaw \& Huang, 2005), it is of further interest to investigate if social contacts at the workplace are associated with expectations of RTW among longterm sick-listed workers.

The workplace actors in focus here are the supervisor, human resources management (HRM), occupational health services (OHS), the labour union representative (LUR) and co-workers.

\section{Aim}

The dual aim of the study was firstly to investigate the pattern and quality of the contact between the employee on long-term sick leave and his/her supervisor, HRM, OHS, LUR, and with his/her co-workers; and secondly to investigate whether contact with the workplace was associated with the sick-listed individual's expectations of RTW.

\section{Method}

Given the limited knowledge regarding contact between employee and workplace during long-term sickness absence, the first aim was investigated by using an explorative and descriptive design. For the second aim, the data was analysed in biviariate and multivariate models. This is the first of a series of studies in a more comprehensive research project that includes both quantitative and qualitative data.

\section{Study Setting}

The Swedish sickness insurance system is tax-based and covers the whole working population (16-65 years of age). After a period of seven days of self-certification, work disability must be confirmed by a physician in a sickness certificate, which is sent to the Social Insurance Agency. This agency makes a decision on entitlement to sickness benefit, based on an assessment of work ability. The employer has to pay the employee's wages for the first 14 days of sick leave, except for a first qualifying day. Sickness benefit is income-related and covers $80 \%$ of the individual's income. Varying percentages of sickness benefit can be granted: $25 \%, 50 \%$ or $100 \%$.

\section{Workplace Actors and Return to Work in the Swedish Context}

Supervisor

In Sweden, the employer/supervisor has considerable legal responsibilities in the RTW process. Both the Swedish Work Environment Act 1977 (Arbetsmiljölagen) and the National Insurance Act 1992 require employers/supervisors to adapt work conditions to the capacity of the individual worker whenever possible. The employer is required to systematically plan, direct and control activities in a manner that leads to a good working environment and, at an early stage in a case of sickness absence, look into the potential need for rehabilitation or other possible measures to facilitate RTW. The growing number of studies in this area indicates that supervisors play a significant role in the RTW process (Tjulin, 2010).

\section{Human Resources Management}

Most companies and organisations of any size have a separate HRM department for the management of their workforce. In general, HRM is responsible for recruitment, training, and assessment of employees, but should also oversee organisational leadership and culture, and ensure compliance with employment and labour laws. Since the 1990s, disability management (DM) has become a central part of HRM, both in Sweden and internationally (Shrey \& Hursh, 1999), and the role of $\mathrm{DM}$ is to focus on absences from work as a result of illness, injury or disability, and on preventing the risks that cause these absences.

\section{Occupational Health Services}

In Sweden there is a long tradition of providing OHS in the workplace. The role of OHS is to ensure a good working environment, and to act as an independent authority for the employer to consult on issues of working health and RTW (Work Environment Act 1977). In 2013, all public companies and organisations in Sweden have contracts with OHS of different kinds, both public and private, and the same is true for the greater majority of the larger private companies. Fewer of the smaller private companies have OHS contracts. In total, it is estimated that around $65 \%$ of all employees in Sweden are employed by companies or organisations that have a contract with an OHS provider (Svensk Företagshälsovård, 2015).

\section{Labour Union Representative}

The labour unions in Sweden are also well established. Despite a decline in membership during recent years, especially among younger workers, the number of employees who are members is high by international standards. In 2012, it was estimated that around 70\% of all workers in Sweden were members of a union. The unions are represented at the workplace by an LUR, whose role is to represent the employees in issues regarding the working environment. Swedish law requires any workplace, private or public, with more than five employees to have an LUR (Work Environment Act 1977, Sweden). Some of the main responsibilities for 
the LUR are securing a good working environment; ensuring that disability management works in a systematic and proper way; and acting as advocate in the RTW process. The LUR plays an important role in activities connected with the working environment and issues concerning RTW.

\section{Co-Workers}

Co-workers have no formal responsibilities in the RTW process, but recent studies (e.g., Dunstan \& MacEachen, 2013a; MacEachen et al., 2006) show that co-workers have a significant role to play in the RTW process. Injured workers who experience support from their coworkers are more likely to RTW, and conversely, lack of support is associated with longer work absence and RTW problems. In a thesis by Tjulin (2010), the roles of different workplace actors are highlighted, and in particular, the positive contribution of co-workers in the RTW process.

The various actors at a workplace have different roles and responsibilities, as well as different perspectives or interests in the RTW process. To the authors' knowledge, there are to date no comprehensive studies investigating the degree to which these different actors communicate with individual employees during a long period on sick leave.

\section{Procedures, Participants and Non-Respondents}

A survey was sent by post to 1112 randomly selected sick-listed people in Sweden, identified by the Social Insurance Agency. For inclusion in this survey, the sicklisted individual was on full sickness absence in February 2012; on sick leave between 60 and 90 days; and permanently employed. The survey was posted to individuals in April 2012, and answered and returned by 390 individuals, which was $35 \%$ of the original distribution. After two reminders, the response rate was $45 \%(n=$ 502). In order to increase the response rate further, a shortened version of the survey was distributed in June, which in August 2012 resulted in a total of 534 answered surveys (i.e., a total response rate of $48 \%$ ). There were no significant differences regarding age and sex between responders and non-responders. The diagnoses among those who responded are well in line with those of the average Swede on long-term sick leave (National Social Insurance, 2011).

\section{Survey}

The survey included questions on demographics, workplace contact, and health and work ability.

\section{Demographics}

In addition to sex, and age (with age ranges defined as16-30, 31-45, 46-65), the questionnaire included items on country of birth (Sweden, abroad), marital status (single, married/living together, relationship but living apart), employment status (permanently employed, not permanently employed), education and occupation. Education was classified into primary education, secondary education, university degree, and 'other'. Occupations were classified into four categories: (a) managers, (b) occupations requiring a long theoretical education, (c) occupations requiring a short theoretical education, (d) and occupations not requiring a theoretical education.

\section{Workplace Contact}

The survey focused on the employees' contact with different workplace actors and included questions, formulated by the authors, such as:

- Have you during your time on sickness absence been in contact with your supervisor? [yes/no]

- Who took initiative for first contact? [the supervisor $\mathrm{did} / \mathrm{I} \mathrm{did]}$

- Are you satisfied with the amount of contact? [yes/no].

\section{Health and Work Ability}

The survey included questions on diagnosis, self-rated health and perceived work ability. Diagnoses were classified into six main categories: (a) musculoskeletal problems, (b) mental disorders, (c) cardiovascular diseases, (d) physical trauma, (e) cancer, and (f) other problems. The categories of musculoskeletal problems and mental disorders were chosen because they constitute the two by far greatest diagnostic categories among the longterm sick. The categories cardiovascular disease, physical trauma, and cancer were chosen because a large majority of the remaining individuals fell into one of these categories; the ones that did not were classified as having other problems. Self-rated health was measured with the EQ visual analogue scale (EQ-VAS; EuroQol Group, 1990) that measures overall mental and physical health on a scale ranging from the worst state imaginable (0) to the best state imaginable (100). Work ability was measured with the Work Ability Index (WAI; Tuomi, Ilmarinen, Jahkola, Katajarinne, \& Tulkki, 1998), which was originally an instrument with seven items and a 5point Likert response scale. In the present study, five of the items were included, covering present work ability, work ability in relation to physical and mental demands at work, prospects of future work ability and optimism.

\section{Outcome Variable 'Expectations'}

To create an outcome variable reflecting 'expectations regarding return to work', three separate questions from the survey were averaged into an index (Cronbach's alpha .66) based on factor analysis. The three questions were: 
- During the last few months, have you felt optimistic regarding the future? (response scale ranging from 1 [often] to 5 [never])

- What are your chances of being able to work in six months from now? (response scale ranging from 1 [great chances] to 5 [very small chances])

- Given your health status, do you think you will be in your current job two years from now? (response scale ranging from 1 [hardly so] to 3 [most likely]).

\section{Data Analysis}

Data were coded in SPSS. For the first aim (i.e., to investigate the pattern and quality of the contact between the employee on long-term sick leave and different workplace actors), the descriptive data were analysed using $t$ test, Wilcoxon test, chi-square test, Kruskal-Wallis test, Mann-Whitney U test, and Fisher's exact test. For the second aim (i.e., to investigate whether contact with the workplace was associated with the individual's expectations of RTW), a chi-square test was used in the bivariate analyses, and a logistic regression model in the multivariate analyses. In the logistic regression model, adjustments were made for sex, age, country of birth, marital status, employment status, occupation, and diagnosis.

\section{Ethics Approval}

Ethics approval was obtained from the Regional Board of Ethics at Linköping University (2010/375-31).

\section{Results}

As can be seen in Table 1, there were only minor differences between men and women in the sample. Men more often had a primary education $(p=.001)$, while women more often had a university education $(p<$ .001). Regarding occupational status, men were more often managers $(p=.003)$, and more often had an occupation not requiring a theoretical education $(p<.001)$, while women more often had an occupation requiring a long education $(p<.001)$. Men had more musculoskeletal diagnoses $(p=.03)$, more cardiovascular diagnoses $(p=.003)$, and other diagnoses $(p=.02)$, while women had more mental disorders $(p<.001)$.

\section{Employees' Contact With Workplace Actors}

Table 2 shows the results for contact between the employees on long-term sick leave and the different workplace actors. The results are presented based on the total group.

In the following result presentation, only detected differences are pointed out. The variables sex, age, education, perceived health, and working ability are included in the analyses, but when not mentioned, no statistical differences were detected.

\section{Contact With a Supervisor}

As can be seen in Table 2, the majority (93\%) of all employees had been in contact with their supervisor while they were on sick leave. It was found that employees with mental disorders had been in contact with their supervisor less often than others $(p=.045)$.

In relation to the number of contacts with a supervisor, and the point when contact was established, younger employees were more often in contact with their supervisor than older employees $(p=.018)$. Regarding the support they experienced from the supervisor, it was found that employees with perceived better health $(p=.002)$ and better working ability $(p=.008)$ experienced that contact with the supervisor was more supportive. When asked about the subject of communication, 55\% reported that they had discussed work adjustments to be able to RTW. Some examples of issues discussed were change of work tasks, greater variations in work, changes in working hours, greater influence in planning of work, and possibility of being replaced.

From an employee perspective, contact with the supervisor was experienced as central to RTW. In response to the statement 'In general, I believe that contact with a supervisor during a period of sickness absence facilitates RTW', $83 \%$ of the respondents $(n=534)$ clearly agreed, while 10\% disagreed (7\% answered 'Do not know'). When responding to the statement 'I have felt needed/asked for by my supervisor/employer during my time on sick leave', 58\% agreed, while 32\% disagreed (10\% answered 'Do not know').

Of the employees who had not been in contact with the supervisor $(n=39)$, 50\% said that they would have liked to be in contact. There were different reasons for not having been in contact (e.g., no interest on the part of the employer, change of job, old-age retirement).

\section{Contact With Human Resources}

A total of $46 \%$ of the employees had been in contact with an organisation's HRM section (see Table 2). Most of those who had been in contact with HRM had two to four meetings, and a majority (82\%) was satisfied with the amount of contact. Regarding the point when contact was established among those who had been in contact with HRM, it was found that employees with better perceived health had earlier contact with HRM than others $\mathrm{did}(p=.045)$. In relation to the quality of contact, the majority (65\%) experienced HRM contact as supportive and helpful, 52\% experienced HRM contact as engaged and involved, and 40\% experienced HRM contact as constructive. Of the employees who had not been in contact with HRM, 22\% said that they would have liked to be in contact.

\section{Contact with Occupational Health Services}

Only a minority (20\%) of the employees had been in contact with OHS (see Table 2). Regarding diagnoses, 
TABLE 1

Background Data

\begin{tabular}{|c|c|c|c|}
\hline Total Respondents $(n=531)^{\mathrm{a}}$ & $\operatorname{Men}(n=215)$ & Women $(n=316)$ & $p$ value ${ }^{b}$ \\
\hline \multicolumn{4}{|l|}{ Age, years $(n=528)$} \\
\hline Mean (range) & $51.7(23-65)$ & $50.3(21-65)$ & 0.16 \\
\hline \multicolumn{4}{|l|}{ Education $(n=528)$} \\
\hline Primary education & $60(28 \%)$ & $52(17 \%)$ & \multirow[t]{4}{*}{$<.001$} \\
\hline Secondary education & $109(51 \%)$ & $153(49 \%)$ & \\
\hline University degree & $34(16 \%)$ & $105(33 \%)$ & \\
\hline Other & $10(5 \%)$ & $5(1 \%)$ & \\
\hline \multicolumn{4}{|l|}{ Nationality $(n=531)$} \\
\hline Born in Sweden & $186(87 \%)$ & $271(86 \%)$ & .81 \\
\hline \multicolumn{4}{|l|}{ Marital status $(n=529)$} \\
\hline Married or living with partner & $156(73 \%)$ & $217(69 \%)$ & \multirow[t]{2}{*}{.64} \\
\hline Single household & $50(23 \%)$ & $76(24 \%)$ & \\
\hline \multicolumn{4}{|l|}{ Occupational status $(n=500)$} \\
\hline Manager & $15(8 \%)$ & $6(2 \%)$ & \multirow[t]{4}{*}{$<.001$} \\
\hline Occupation requiring long theoretical education & $17(9 \%)$ & $74(25 \%)$ & \\
\hline Occupation requiring short theoretical education & $22(11 \%)$ & $52(17 \%)$ & \\
\hline Occupation requiring no theoretical education & $146(73 \%)$ & $168(56 \%)$ & \\
\hline \multicolumn{4}{|l|}{ Employment status $(n=530)$} \\
\hline Permanently employed & $193(90 \%)$ & $278(88 \%)$ & .59 \\
\hline \multicolumn{4}{|l|}{ Diagnoses $(n=508)$} \\
\hline Musculoskeletal & $85(41 \%)$ & $96(32 \%)$ & \multirow[t]{6}{*}{$<.001$} \\
\hline Physical trauma & $34(16 \%)$ & $39(13 \%)$ & \\
\hline Mental disorders & $23(11 \%)$ & $82(27 \%)$ & \\
\hline Cancer & $17(8 \%)$ & $40(13 \%)$ & \\
\hline Cardiovascular disease & $23(11 \%)$ & $13(4 \%)$ & \\
\hline Other & $25(12 \%)$ & $9(6 \%)$ & \\
\hline
\end{tabular}

Note: ${ }^{a}$ The total number was 534, but three respondents did not provide data on their sex. ${ }^{b}$ Student's $t$ test for age and chi-squared test for categorical variables.

it was found that employees with mental disorders were in contact with OHS more than twice as often (43\%) as others $(p<.001)$. This was the case among both men $(p=.001)$ and women $(p=.001)$. In regard to frequency of contacts with OHS, women were found to have had more frequent contact with OHS than men had $(p=.005)$ and employees reporting worse health were also more frequently in contact with OHS $(p=.021)$. Regarding the point when contact was established (among those who had been in contact) a tendency was that women tended to have more contact with OHS earlier in the sickness period than did men $(p=.065)$. Those who had been in contact with OHS, especially employees with mental diagnoses, were satisfied with the quality of the contact, and the great majority found OHS supportive.

Of those who had not been in contact with OHS, $27 \%$ said that they would have liked to be in contact. The reported reasons for not having been in contact with OHS varied. Many reported that there was no need to involve OHS (often because they were in direct contact with a general practitioner); others said that it had simply not happened, and still others that the company had no OHS.

\section{Contact With the Labour Union Representative}

A minority (34\%) of the employees had been in contact with the LUR. It was found that employees reporting worse health and lower working ability were more often in contact with the LUR $(p=.001)$. There was also a tendency, however not statistically significant, that younger employees were less often in contact with the LUR than older employees $(p=.054)$.

Regarding when contact was established it was found that employees reporting 'physical trauma' were in contact with the LUR significantly earlier $(p=.001)$ than others. Of the employees who had not been in contact with the LUR, 20\% said that they would have liked to be in contact. 
TABLE 2

Employees' Contact With Different Workplace Actors During Long-Term Sickness Absence

\begin{tabular}{|c|c|c|c|c|c|}
\hline & $\begin{array}{l}\text { Supervisor } \\
{[n=529]}\end{array}$ & $\begin{array}{l}\text { HRM } \\
{[n=445]}\end{array}$ & $\begin{array}{l}\text { OHS } \\
{[n=453]}\end{array}$ & $\begin{array}{l}\text { LUR } \\
{[n=450]}\end{array}$ & $\begin{array}{l}\text { Co-Workers } \\
{[n=526]}\end{array}$ \\
\hline Employees that had been in contact with .... & $\begin{array}{l}93 \% \\
{[91,96]}\end{array}$ & $\begin{array}{l}46 \% \\
{[41,50]}\end{array}$ & $\begin{array}{l}20 \% \\
{[16,24]}\end{array}$ & $\begin{array}{l}34 \% \\
{[30,39]}\end{array}$ & $\begin{array}{l}92 \% \\
{[89,94]}\end{array}$ \\
\hline \multicolumn{6}{|c|}{ Number of contacts (among those who had been in contact) } \\
\hline In contact once & $\begin{array}{l}5 \% \\
{[3,7]}\end{array}$ & $\begin{array}{l}23 \% \\
{[17,29]}\end{array}$ & $\begin{array}{l}18 \% \\
{[10,27]}\end{array}$ & $\begin{array}{l}34 \% \\
{[27,42]}\end{array}$ & $\begin{array}{l}4 \% \\
{[2,6]}\end{array}$ \\
\hline 2 to 4 times & $\begin{array}{l}41 \% \\
{[37,46]}\end{array}$ & $\begin{array}{l}52 \% \\
{[44,59]}\end{array}$ & $\begin{array}{l}41 \% \\
{[31,52]}\end{array}$ & $\begin{array}{l}54 \% \\
{[46,62]}\end{array}$ & $\begin{array}{l}26 \% \\
{[22,30]}\end{array}$ \\
\hline More than 4 times & $\begin{array}{l}53 \% \\
{[49,58]}\end{array}$ & $\begin{array}{l}26 \% \\
{[20,32]}\end{array}$ & $\begin{array}{l}40 \% \\
{[30,51]}\end{array}$ & $\begin{array}{l}11 \% \\
{[6,17]}\end{array}$ & $\begin{array}{l}70 \% \\
{[66,74]}\end{array}$ \\
\hline \multicolumn{6}{|l|}{ When was first contact established? } \\
\hline During the first 2 weeks & $\begin{array}{l}70 \% \\
{[66,74]}\end{array}$ & $\begin{array}{l}49 \% \\
{[42,56]}\end{array}$ & $\begin{array}{l}59 \% \\
{[48,69]}\end{array}$ & $\begin{array}{l}38 \% \\
{[31,46]}\end{array}$ & $\begin{array}{l}67 \% \\
{[63,71]}\end{array}$ \\
\hline During weeks 3 to 6 & $\begin{array}{l}22 \% \\
{[19,26]}\end{array}$ & $\begin{array}{l}28 \% \\
{[21,34]}\end{array}$ & $\begin{array}{l}18 \% \\
{[10,27]}\end{array}$ & $\begin{array}{l}32 \% \\
{[25,40]}\end{array}$ & $\begin{array}{l}26 \% \\
{[22,30]}\end{array}$ \\
\hline Later & $\begin{array}{l}8 \% \\
{[5,10]}\end{array}$ & $\begin{array}{l}23 \% \\
{[17,29]}\end{array}$ & $\begin{array}{l}23 \% \\
{[14,32]}\end{array}$ & $\begin{array}{l}29 \% \\
{[22,36]}\end{array}$ & $\begin{array}{l}7 \% \\
{[5,9]}\end{array}$ \\
\hline \multicolumn{6}{|l|}{ Who took the initiative for the first contact? } \\
\hline The employee on sick leave did & $\begin{array}{l}53 \% \\
{[49,58]}\end{array}$ & $\begin{array}{l}66 \% \\
{[60,73]}\end{array}$ & $\begin{array}{l}67 \% \\
{[57,77]}\end{array}$ & $\begin{array}{l}85 \% \\
{[79,91]}\end{array}$ & $\begin{array}{l}38 \% \\
{[34,42]}\end{array}$ \\
\hline \multicolumn{6}{|l|}{ Were you pleased with the amount of contact? } \\
\hline Yes & $\begin{array}{l}81 \% \\
{[77,84]}\end{array}$ & $\begin{array}{l}83 \% \\
{[77,88]}\end{array}$ & $\begin{array}{l}79 \% \\
{[70,88]}\end{array}$ & $\begin{array}{l}76 \% \\
{[69,83]}\end{array}$ & $\begin{array}{l}86 \% \\
{[83,89]}\end{array}$ \\
\hline No, too little & $17 \%$ & $15 \%$ & $20 \%$ & $22 \%$ & $12 \%$ \\
\hline No, too much & $\begin{array}{l}{[14,21]} \\
2 \% \\
{[1,3]}\end{array}$ & $\begin{array}{l}{[10,20]} \\
2 \% \\
{[0,4]}\end{array}$ & $\begin{array}{l}{[11,28]} \\
1 \% \\
{[-1,3]}\end{array}$ & $\begin{array}{l}{[16,29]} \\
1 \% \\
{[0,3]}\end{array}$ & $\begin{array}{l}{[9,15]} \\
2 \% \\
{[1,3]}\end{array}$ \\
\hline \multicolumn{6}{|l|}{ Were you pleased with the quality of the contact? } \\
\hline Yes, I found it really supportive & $\begin{array}{l}63 \% \\
{[59,68]}\end{array}$ & $\begin{array}{l}65 \% \\
{[58,72]}\end{array}$ & $\begin{array}{l}76 \% \\
{[67,86]}\end{array}$ & $\begin{array}{l}67 \% \\
{[59,75]}\end{array}$ & $\begin{array}{l}80 \% \\
{[77,84]}\end{array}$ \\
\hline Yes, I found it really constructive & $\begin{array}{l}35 \% \\
{[30,40]}\end{array}$ & $\begin{array}{l}40 \% \\
{[32,47]}\end{array}$ & $\begin{array}{l}46 \% \\
{[35,57]}\end{array}$ & $\begin{array}{l}34 \% \\
{[26,43]}\end{array}$ & $\begin{array}{l}34 \% \\
{[30,39]}\end{array}$ \\
\hline \multicolumn{6}{|l|}{ Have you had a personal meeting? } \\
\hline Yes & $\begin{array}{l}68 \% \\
{[64,72]}\end{array}$ & $\begin{array}{l}53 \% \\
{[46,60]}\end{array}$ & $\begin{array}{l}79 \% \\
{[71,88]}\end{array}$ & $\begin{array}{l}39 \% \\
{[31,47]}\end{array}$ & $\begin{array}{l}77 \% \\
{[73,81]}\end{array}$ \\
\hline \multicolumn{6}{|c|}{ Have you discussed how to modify your work to facilitate RTW? } \\
\hline Yes & $\begin{array}{l}47 \% \\
{[42,51]}\end{array}$ & $\begin{array}{l}34 \% \\
{[27,40]}\end{array}$ & $\begin{array}{l}58 \% \\
{[47,68]}\end{array}$ & $\begin{array}{l}21 \% \\
{[14,27]}\end{array}$ & $\begin{array}{l}33 \% \\
{[28,37]}\end{array}$ \\
\hline
\end{tabular}

Note: Based on $n=534$; proportions with $95 \%$ confidence intervals.

\section{Contact With Co-Workers}

The majority (92\%) of all employees had been in contact with their co-workers during their time on sick leave (see Table 2). Regarding timing and frequency of contacts with co-workers, no differences were detected. It was found that women experienced more support from co-workers $(p=.011)$, and more engaged and involved co-workers $(p=.001)$, than men did. Most respondents were satisfied or very satisfied with the quality of the contact with their co-workers; $90 \%$ experienced the contact as 'inviting', $80 \%$ as 'supportive' and $75 \%$ as 'helpful'. Only a few reported that they were clearly dissatisfied (2\%), but some reported that they experienced the contact as not so constructive (24\%). Concerning the subject of communication, $41 \%$ reported that they 
had discussed work adjustments, e.g. change of work tasks $(13 \%)$ and possibilities of having more recovery at work $(6 \%)$.

From an employee perspective, contact with coworkers is experienced as central to RTW. In response to the statement 'In general, I believe that contact with co-workers while they are on sick leave facilitates RTW', 86\% clearly agreed, while only $8 \%$ disagreed (6\% answered 'Do not know'). When responding to the statement 'I have felt needed/asked for by my coworkers during my time on sick leave', $74 \%$ agreed, while 18\% disagreed ( $8 \%$ answered 'Do not know'). It was more common among women than among men to have felt needed and asked for by co-workers $(p=.044)$.

Of the few who had not been in contact $(n=45)$, $47 \%$ said that they would have liked to be in contact. The reasons for not having been in contact varied (e.g., having no colleagues, having been in hospital, and living far away from work).

Co-worker contact was positively associated with supervisor contact. Employees who had been in contact with their co-workers, had also been in contact with the supervisor $(p=.009)$, and employees who experienced the contact with their co-workers as constructive and supportive, also experienced the contact with their supervisor as constructive and supportive $(p<.001)$.

\section{Contact and Expectations of Return to Work}

In the bivariate and multivariate analyses focusing on contact and expectations of RTW, only contacts with the supervisor and co-workers are included. The reason for this was that it was with the supervisors and the co-workers that most individuals had been in contact. Contact with the other workplace actors was more sparse. The results from the bivariate analysis are shown in Table 3 and Table 4. The tables should be read from left to right (e.g., $52 \%$ of the employees who had been in contact with their supervisor were optimistic regarding the future). As can be seen in Table 3, employees who had early and more intense contact with their supervisor were more positive and optimistic regarding the future and RTW than employees who had later and less intense contact. Furthermore, the quality of the contact seems to be of importance. Employees who experienced their contact with the supervisor as supportive and constructive were also more optimistic than others regarding the future and RTW, whether or not they had a personal meeting with the supervisor seemed to be of minor importance.

As can be seen in Table 4, there are similar associations for contact with co-workers, indicating that employees who had contact, and had early and more frequent contact with co-workers, were more positive and optimistic than other employees regarding the future and RTW. Table 4 also shows that the quality of the contact is important. Employees who experienced the contact with their co-workers as supportive and constructive were more optimistic than others regarding the future and RTW. Whether or not they had a personal meeting with co-workers seemed to be of minor importance.

In the logistic regression analysis (see Table 5), only a few findings from the bivariate analyses remained after controlling for potential confounders (including background variables), and these are all quality-related. Employees who experienced the contacts with their supervisors as supportive, OR 82.70, 95\% CI [9.98, 685.36]; and constructive, OR $14.44,95 \%$ CI [6.45, 32.32]; and the contacts with their co-workers as constructive, OR $3.07,95 \%$ CI $[1.70,5.5]$, were more optimistic regarding RTW than others.

In an attempt to further understand these results, the dominant variables 'supportive' and 'constructive' were removed from the regression models, opening for potential associations with other variables and variables associated with supportive and constructive. The results from these new models showed that the number of contacts with a supervisor $(p=.011)$, if the employee was contacted by the supervisor $(p=.029)$, if work adjustment was discussed with the supervisor $(p=.037)$, and if the employee had a long theoretical education $(p=.019)$ were all positively associated with RTW expectations, and that mental disorders $(p=.014)$ were negatively associated with RTW expectations.

\section{Discussion}

A major finding was that a majority of employees have frequent and, in most cases, appreciated contact with their supervisor and co-workers during long-term absence from work, and that employees who experience the contact as supportive and constructive are more positive and optimistic than others, regarding RTW. The number of contacts, whether they were early or not, and whether there had been a personal meeting or not, seemed to be of minor importance. Instead, quality of contact seems to be what matters. The results also show that supportive organisations such as HRM, OHS and the LUR are considerably less in contact with the employee in the RTW process than supervisors and coworkers.

\section{Supervisor Contact}

The results from the study indicate that contact with the supervisor is frequent and, from an employee perspective, satisfactory. This finding is in line with the intentions as stated in Swedish laws and regulations (i.e., that the supervisor and the employee must communicate early in the RTW process). Furthermore, the results are encouraging as they indicate that supervisors are often not only involved 'as an official party' (discussing work-related issues), but also as a 'social support' (the frequency of contact and the finding that the 
TABLE 3

Associations Between Contact With Supervisor and Three Outcome Variables

\begin{tabular}{|c|c|c|c|c|c|c|c|c|c|}
\hline & \multicolumn{3}{|c|}{$\begin{array}{l}\text { During the last month, have you } \\
\text { felt optimistic regarding the future? }\end{array}$} & \multicolumn{3}{|c|}{$\begin{array}{l}\text { Do you have good/great chances to } \\
\text { be able to work in } 6 \text { months time? }\end{array}$} & \multicolumn{3}{|c|}{$\begin{array}{l}\text { Given your health, do you think you } \\
\text { will work in } 2 \text { years time? }\end{array}$} \\
\hline & Yes & No & $p$ value $^{a}$ & Yes & No & $p$ value $^{a}$ & Yes & No & $p$ value $^{a}$ \\
\hline \multicolumn{10}{|c|}{ Have you had any contact? } \\
\hline Yes & $251(52 \%)$ & $233(48 \%)$ & .83 & $353(72 \%)$ & $137(28 \%)$ & .20 & $413(85 \%)$ & $71(15 \%)$ & .07 \\
\hline No & $17(50 \%)$ & $17(50 \%)$ & & $21(62 \%)$ & $13(38 \%)$ & & $25(74 \%)$ & $9(26 \%)$ & \\
\hline \multicolumn{10}{|l|}{ Number of contacts } \\
\hline Once & $14(54 \%)$ & $12(46 \%)$ & .14 & $11(42 \%)$ & $15(58 \%)$ & .002 & $17(65 \%)$ & $9(35 \%)$ & .01 \\
\hline 2 to 4 times & $91(46 \%)$ & $105(54 \%)$ & & $146(73 \%)$ & $53(27 \%)$ & & $167(85 \%)$ & $29(15 \%)$ & \\
\hline More than 4 times & $141(56 \%)$ & $112(44 \%)$ & & $190(74 \%)$ & $66(26 \%)$ & & $221(87 \%)$ & $32(13 \%)$ & \\
\hline \multicolumn{10}{|c|}{ When was the first contact established? } \\
\hline $\begin{array}{l}\text { During the first } 2 \\
\text { weeks }\end{array}$ & $183(55 \%)$ & $149(45 \%)$ & .02 & $252(76 \%)$ & $81(24 \%)$ & .02 & $292(88 \%)$ & $40(12 \%)$ & .001 \\
\hline During weeks 3 to 6 & $51(49 \%)$ & $54(51 \%)$ & & $73(68 \%)$ & $34(32 \%)$ & & $86(83 \%)$ & $18(17 \%)$ & \\
\hline Later & $11(31 \%)$ & $24(69 \%)$ & & $20(56 \%)$ & $16(44 \%)$ & & $23(66 \%)$ & $12(34 \%)$ & \\
\hline \multicolumn{10}{|c|}{ Who took the initiative for the first contact? } \\
\hline $\begin{array}{l}\text { The employee on sick } \\
\text { leave did }\end{array}$ & $128(51 \%)$ & $122(49 \%)$ & .67 & $182(72 \%)$ & $70(28 \%)$ & .75 & $211(84 \%)$ & $39(16 \%)$ & .46 \\
\hline Supervisor & $117(53 \%)$ & $103(47 \%)$ & & $164(73 \%)$ & $59(27 \%)$ & & $191(87 \%)$ & $29(13 \%)$ & \\
\hline \multicolumn{10}{|c|}{ Were you pleased with the amount of contact? } \\
\hline Yes & $211(56 \%)$ & $168(44 \%)$ & .002 & $284(74 \%)$ & $101(26 \%)$ & .12 & $328(87 \%)$ & $51(13 \%)$ & .30 \\
\hline No, too little & $31(38 \%)$ & $51(62 \%)$ & & $57(69 \%)$ & $25(31 \%)$ & & $66(81 \%)$ & $16(19 \%)$ & \\
\hline No, too much & $2(22 \%)$ & $7(78 \%)$ & & $4(44 \%)$ & $5(56 \%)$ & & $7(78 \%)$ & $2(22 \%)$ & \\
\hline \multicolumn{10}{|c|}{ Were you pleased with the quality of the contact? } \\
\hline $\begin{array}{l}\text { Yes, I found it } \\
\text { really supportive }\end{array}$ & $163(58 \%)$ & $117(42 \%)$ & .002 & $219(77 \%)$ & $65(23 \%)$ & .01 & $254(90 \%)$ & $27(10 \%)$ & .001 \\
\hline $\begin{array}{l}\text { No, I did not find it } \\
\text { supportive }\end{array}$ & $69(43 \%)$ & $93(57 \%)$ & & $107(66 \%)$ & $55(34 \%)$ & & $128(80 \%)$ & $33(20 \%)$ & \\
\hline \multicolumn{10}{|c|}{ Were you pleased with the quality of the contact? } \\
\hline $\begin{array}{l}\text { Yes, I found it really } \\
\text { constructive }\end{array}$ & $90(64 \%)$ & $50(36 \%)$ & .001 & $109(77 \%)$ & $32(23 \%)$ & .24 & $127(91 \%)$ & $13(9 \%)$ & .04 \\
\hline $\begin{array}{l}\text { No, I did not find it } \\
\text { constructive }\end{array}$ & $122(47 \%)$ & $138(53 \%)$ & & $187(72 \%)$ & $73(28 \%)$ & & $215(83 \%)$ & $43(17 \%)$ & \\
\hline \multicolumn{10}{|c|}{ Have you had a personal meeting? } \\
\hline Yes & $169(52 \%)$ & $156(48 \%)$ & .89 & $235(71 \%)$ & $94(29 \%)$ & .66 & $274(85 \%)$ & $50(15 \%)$ & .50 \\
\hline No & $78(51 \%)$ & $74(49 \%)$ & & $113(73 \%)$ & $41(27 \%)$ & & $133(87 \%)$ & $20(13 \%)$ & \\
\hline \multicolumn{10}{|c|}{ Have you discussed how to modify your work to facilitate RTW? } \\
\hline Yes & $120(52 \%)$ & $109(48 \%)$ & .82 & $181(79 \%)$ & $49(21 \%)$ & .002 & $201(89 \%)$ & $26(12 \%)$ & .06 \\
\hline No & $131(51 \%)$ & $124(49 \%)$ & & $172(66 \%)$ & $88(34 \%)$ & & $212(83 \%)$ & $45(17 \%)$ & \\
\hline
\end{tabular}

Note: a Chi-squared test or Fisher's exact test.

employees are satisfied). The significance of the supervisor being involved in the RTW process is shown in many studies (Flach, Groothoff, Bultman, 2013; Kosny et al., 2013; MacEachen et al., 2006, Nordqvist, Holmqvist, \& Alexanderson, 2003; Shaw, Robertson, Pransky, \& McLellan, 2003; Tjulin et al. 2010; Young, 2010), and this study also indicates that supervisors do actually understand their central role. Supervisor involvement is central in many respects to RTW. Beside his/her supportive role, the supervisor is often in a position to implement and monitor modified work (Shaw et al., 2003), and is often able to understand any potentially problematic social dynamics between the re-entering worker and other co-workers (Nordqvist et al., 2003). The relationship between supervisors and employees has a bearing on organisational culture and general attitudes towards RTW. However, several studies also show supervisory obstacles to facilitating the RTW process (MacEachen et al., 2006), such as lack of skills and training for managing RTW (Baril et al., 2003), lack 
TABLE 4

Associations Between Contact With Co-Workers and Three Outcome Variables

\begin{tabular}{|c|c|c|c|c|c|c|c|c|c|}
\hline & \multicolumn{3}{|c|}{$\begin{array}{l}\text { During the last month, have you } \\
\text { felt optimistic regarding the future? }\end{array}$} & \multicolumn{3}{|c|}{$\begin{array}{l}\text { Do you have good/great chances to } \\
\text { be able to work in } 6 \text { months time? }\end{array}$} & \multicolumn{3}{|c|}{$\begin{array}{c}\text { Given your health, do you think you } \\
\text { will work in } 2 \text { years time? }\end{array}$} \\
\hline & Yes & No & $p$ value $^{a}$ & Yes & No & $p$ value $^{a}$ & Yes & No & $p$ value $^{a}$ \\
\hline \multicolumn{10}{|c|}{ Have you had any contact? } \\
\hline Yes & $247(52 \%)$ & $225(48 \%)$ & .31 & $349(73 \%)$ & $130(27 \%)$ & .01 & $399(85 \%)$ & $72(15 \%)$ & .86 \\
\hline No & $19(44 \%)$ & $24(56 \%)$ & & $23(55 \%)$ & $19(45 \%)$ & & $36(84 \%)$ & $7(16 \%)$ & \\
\hline \multicolumn{10}{|l|}{ Number of contacts } \\
\hline Once & $6(33 \%)$ & $12(67 \%)$ & .10 & $9(47 \%)$ & $10(53 \%)$ & .03 & $14(78 \%)$ & $4(22 \%)$ & .42 \\
\hline 2 to 4 times & $59(48 \%)$ & $63(52 \%)$ & & $89(72 \%)$ & $35(28 \%)$ & & $101(83 \%)$ & $21(17 \%)$ & \\
\hline More than 4 times & $181(55 \%)$ & $146(45 \%)$ & & $247(75 \%)$ & $83(25 \%)$ & & $281(87 \%)$ & $44(13 \%)$ & \\
\hline \multicolumn{10}{|c|}{ When was the first contact established? } \\
\hline $\begin{array}{l}\text { During the first } \\
2 \text { weeks }\end{array}$ & $186(60 \%)$ & $126(40 \%)$ & $<.001$ & $239(76 \%)$ & $76(24 \%)$ & .20 & $271(87 \%)$ & $41(13 \%) 2$ & .13 \\
\hline $\begin{array}{l}\text { During week } \\
\quad 3 \text { to } 6\end{array}$ & $51(42 \%)$ & $71(58 \%)$ & & $84(68 \%)$ & $40(32 \%)$ & & $96(79 \%)$ & $5(21 \%)$ & \\
\hline Later & $9(28 \%)$ & $23(72 \%)$ & & $23(70 \%)$ & $10(30 \%)$ & & $28(88 \%)$ & $4(12 \%)$ & \\
\hline \multicolumn{10}{|c|}{ Who took the initiative for the first contact? } \\
\hline $\begin{array}{l}\text { The employee on } \\
\text { sick leave did }\end{array}$ & $97(55 \%)$ & $79(45 \%)$ & .43 & $135(75 \%)$ & $45(25 \%)$ & .57 & $155(88 \%)$ & $21(12 \%)$ & .20 \\
\hline Co-worker & $149(51 \%)$ & $141(49 \%)$ & & $212(73 \%)$ & $80(27 \%)$ & & $242(84 \%)$ & $47(16 \%)$ & \\
\hline \multicolumn{10}{|c|}{ Were you pleased with the amount of contact? } \\
\hline Yes & $221(55 \%)$ & $181(45 \%)$ & .02 & $307(75 \%)$ & $101(25 \%)$ & .01 & $346(87 \%)$ & $54(13 \%)$ & .13 \\
\hline No, too little & $22(39 \%)$ & $35(61 \%)$ & & $32(56 \%)$ & $25(44 \%)$ & & $44(77 \%)$ & $13(23 \%)$ & \\
\hline No, too much & $2(25 \%)$ & $6(75 \%)$ & & $6(75 \%)$ & $2(25 \%)$ & & $6(75 \%)$ & $2(25 \%)$ & \\
\hline \multicolumn{10}{|c|}{ Were you pleased with the quality of the contact? } \\
\hline $\begin{array}{l}\text { Yes, I found it really } \\
\text { supportive }\end{array}$ & $199(56 \%)$ & $159(44 \%)$ & .06 & $276(77 \%)$ & $84(23 \%)$ & .02 & $312(88 \%)$ & $44(12 \%)$ & .02 \\
\hline $\begin{array}{l}\text { No, I didn't find it } \\
\text { supportive }\end{array}$ & $37(44 \%)$ & $47(56 \%)$ & & $56(64 \%)$ & $31(36 \%)$ & & $65(77 \%)$ & $19(23 \%)$ & \\
\hline \multicolumn{10}{|c|}{ Were you pleased with the quality of the contact? } \\
\hline $\begin{array}{l}\text { Yes, I found it really } \\
\text { constructive }\end{array}$ & $86(65 \%)$ & $47(35 \%)$ & .001 & $107(80 \%)$ & $27(20 \%)$ & .07 & $120(91 \%)$ & $12(9 \%)$ & .04 \\
\hline $\begin{array}{l}\text { No, I didn't find it } \\
\text { constructive }\end{array}$ & $120(48 \%)$ & $132(52 \%)$ & & $183(71 \%)$ & $73(29 \%)$ & & $210(83 \%)$ & $42(17 \%)$ & \\
\hline \multicolumn{10}{|c|}{ Have you had a personal meeting? } \\
\hline Yes & $195(54 \%)$ & $168(46 \%)$ & .35 & $272(74 \%)$ & $95(26 \%)$ & .34 & $305(85 \%)$ & $56(15 \%)$ & .41 \\
\hline No & $51(49 \%)$ & $54(51 \%)$ & & $75(69 \%)$ & $33(31 \%)$ & & $93(88 \%)$ & $13(12 \%)$ & \\
\hline \multicolumn{10}{|c|}{ Have you discussed how to modify your work to facilitate RTW? } \\
\hline Yes & $76(56 \%)$ & $60(44 \%)$ & .53 & $106(78 \%)$ & $30(22 \%)$ & .09 & $122(90 \%)$ & $13(10 \%)$ & .09 \\
\hline No & $143(53 \%)$ & $129(47 \%)$ & & 195 (70\%) & $83(30 \%)$ & & $229(84 \%)$ & $43(16 \%)$ & \\
\hline
\end{tabular}

Note: ${ }^{a}$ Chi-squared test or Fisher's exact test.

of time (Nordqvist et al., 2003), and cases where the supervisor regards the responsibilities for RTW as an unwanted burden (Tjulin et al., 2010).

The tendency that employees with mental disorders were less often in contact with their supervisor than others should be taken seriously. There are studies (Brouwer, Reneman, Bultmann, van der Klink, \& Grotthoff, 2010; Glozier, Hough, Henderson, \& HollandElliott, 2006) indicating that employees with mental problems are often 'socially disregarded'. It is also worth noticing that around $30 \%$ of the employees report that they have only felt needed and asked for by their supervisor to a small or relatively small extent during their time on sick leave.

\section{Co-Worker Contact}

The finding regarding early and frequent contact with co-workers is significant. Nine out of ten employees were satisfied with the amount and quality of the 
TABLE 5

Employee Supportive and Constructive Contact with Supervisors and Co-Workers

\begin{tabular}{|c|c|c|c|c|c|c|c|c|}
\hline \multirow[b]{2}{*}{ Variables } & \multicolumn{4}{|c|}{ (1) Social contacts with supervisor $(n=358)$} & \multicolumn{4}{|c|}{ (2) Social contacts with co-workers $(n=321)$} \\
\hline & $N$ & OR & $95 \% \mathrm{Cl}$ & $p$ value & $N$ & OR & $95 \% \mathrm{Cl}$ & $p$ value \\
\hline \multicolumn{9}{|l|}{ Number of contacts } \\
\hline Once & 16 & 1 & & & 12 & 1 & & \\
\hline 2 to 4 times & 145 & 1.39 & {$[0.08,25.59]$} & .83 & 83 & 0.74 & {$[0.10,5.36]$} & .77 \\
\hline More than 4 times & 197 & 1.47 & {$[0.08,29.07]$} & .80 & 226 & 0.49 & $0.07,3.64]$ & .49 \\
\hline \multicolumn{9}{|c|}{ When was the first contact established? } \\
\hline During the first 2 weeks & 259 & 1 & & & 224 & 1 & & \\
\hline During week 3 to 6 & 76 & 0.69 & {$[0.25,1.94]$} & .48 & 74 & 0.78 & {$[0.38,1.61]$} & .50 \\
\hline Later & 23 & 1.83 & {$[0.29,11.55]$} & .52 & 23 & 0.45 & {$[0.12,1.67]$} & .23 \\
\hline \multicolumn{9}{|c|}{ Who took the initiative for the first contact? } \\
\hline Supervisor & 163 & 1 & & & 194 & 1 & & \\
\hline The employee on sick leave & 195 & 0.50 & {$[0.23,1.07]$} & .07 & 127 & 1.58 & {$[0.87,2.89]$} & .14 \\
\hline \multicolumn{9}{|c|}{ Were you pleased with the amount of contact? } \\
\hline No & 75 & 1 & & & 41 & 1 & & \\
\hline Yes & 283 & 4.34 & {$[0.45,42.19]$} & .21 & 280 & 6.36 & {$[1.69,23.92]$} & .006 \\
\hline \multicolumn{9}{|c|}{ Regarding quality, did you find the contact supportive? } \\
\hline No & 140 & 1 & & & 62 & 1 & & \\
\hline Yes & 218 & 82.70 & {$[9.98,685.36]$} & $<.001$ & 259 & 2.48 & {$[0.99,6.19]$} & .052 \\
\hline \multicolumn{9}{|c|}{ Regarding quality, did you find the contact constructive? } \\
\hline No & 236 & 1 & & & 211 & 1 & & \\
\hline Yes & 122 & 14.44 & {$[6.45,32.32]$} & $<.001$ & 110 & 3.07 & {$[1.70,5.54]$} & $<.001$ \\
\hline \multicolumn{9}{|c|}{ Have you had a personal meeting? } \\
\hline No & 117 & 1 & & & 68 & 1 & & \\
\hline Yes & 241 & 1.43 & {$[0.53,3.82]$} & .48 & 253 & 1.41 & {$[0.62,3.21]$} & .42 \\
\hline \multicolumn{9}{|c|}{ Have you discussed how to modify your work to facilitate RTW? } \\
\hline No & 185 & 1 & & & 210 & 1 & & \\
\hline Yes & 173 & 1.36 & {$[0.65,2.87]$} & .42 & 111 & 1.70 & {$[0.93,3.08]$} & .08 \\
\hline
\end{tabular}

Note: Multivariate logistic regression of having a high level of 'optimism regarding job return', predicted by social contacts variables with (1) supervisor and (2) co-workers, among those who have had contact with their supervisor $(n=494)$ and co-workers $(n=483)$, adjusted for background variables (sex, age, country of birth, marital status, occupation, employment status and diagnoses).

contact with co-workers, and none of the employees reported that the contact with their co-workers had been too intense. The majority of employees consider social interaction with co-workers as important and supportive in the RTW process. The results also show that the relationship is established and kept alive not only by the employee, but also by the co-workers. These findings are interesting and encouraging in a social context, since there is evidence that co-workers have a significant role in the RTW process (Kosny et al., 2013). A number of recent studies have found that when injured workers experience support from their co-workers, they are more likely to return to work (Campbell, WynneJones, Muller, \& Dunn, 2013; Clay, Fitzharris, Kerr, McClure, \& Watson, 2012; Haugli, Maeland, \& Magnussen, 2011; Kong et al., 2012); and conversely, lack of support is associated with longer work absence and RTW problems (Katz et al., 2005). It is worth noting, however, that there are studies (Dunstan \& MacEachen, 2013b; Kosny et al., 2013) that focus on the experiences of co-workers, showing that a colleague's RTW can be difficult for co-workers, as they often know little about the RTW process and the injured worker's circumstances. Similar findings are presented by Tjulin (2010), who found that co-workers often felt uncomfortable and uncertain regarding how and when to contact the absent colleague. The results from our study show that co-workers have a key position in the RTW process, and from a disability management perspective, it is therefore of great importance to focus more attention on the role of co-workers in the RTW process.

Another interesting finding was that good contacts with co-workers seem to be associated with good contacts with the supervisor. Employees who had been in contact with their co-workers had also been in contact with their supervisor; and employees who experienced the contact with co-workers as constructive and 
supportive also experienced the contact with the supervisor as constructive and supportive. Conclusions from this crude and rather small bivariate analysis should be drawn with caution, but it can serve as an indication that good workplace contacts can be seen rather as an effect of a 'good working climate', than just separate activities by individuals at the workplace.

\section{Contact With Human Resources Management/Occupational Health Services/ Labour Union Representative}

Contact with HRM was significantly less intense than with the supervisor and co-workers. However, not all employees are employed in a company with a separate HRM department, and among the employees who had access to HRM, but had not been in contact, the reported reasons for not having been in contact seem relevant. An unexpected finding was that such a small percentage $(20 \%)$ of employees had been in contact with OHS. Not all employees have access to OHS, but around $65 \%$ of all employees in Sweden do have access to OHS (Svensk Företagshälsovård, 2015). Since the primarily role of OHS is to act for good working conditions and act as an expert for the employer to consult when it comes to issues regarding working health and RTW (National Insurance Act 1992), it is reasonable to expect that contact between a permanently employed individual and the OHS would be more intense during a period of long-term sickness absence than the results indicate. The results may reflect the present market system for OHS in Sweden, where the employer buys certain services from OHS. When it comes to sickness or injury, the primary health care centres, which are part of the 'free' public welfare system, are also involved. In which case, do both employer and employee instead choose this alternative? A further finding is that employees with mental disorders had significantly more contact with OHS than employees with other types of problems. There are studies that show supervisors feel less competent in handling employees with mental disorders and are more willing to offer them support from the OHS (e.g., Lemieux, Durand, \& Hong, 2011). The limited contact with the LUR is likely to reflect the traditional roles of the unions as guardians of salaries and of employment, rather than as active participants in the RTW process. The LUR may take an active role mainly when the sick-listed person risks dismissal. This would explain the finding that employees with worse health and lower working ability were more often than others in contact with the LUR, since they are at risk of losing their employment.

\section{Contact and Perceived Chance of RTW}

The findings in the bivariate analysis indicating that early and frequent contact with supervisor and coworkers are associated with positive expectations re- garding RTW, do not remain after analysing the data in a multivariate model. The results from the multivariate analyses rather show that contact quality is associated with expectations of RTW. To facilitate positive RTW expectations, focus should not necessarily be on 'early' or 'face-to-face' contact, but instead be on genuine quality. The employee needs to experience constructive and supportive contact with his/her supervisor and co-workers. The results from the modified analysis where the variables 'supportive' and 'constructive' were excluded indicate that the variables that explain this feeling of having supportive and constructive contact are (a) initial contact by the supervisor, (b) frequent contact, and (c) contacts where work adjustment is discussed. These findings are in line with previous research (Tjulin, 2010).

\section{Methodological Issues}

The results are based on a response rate of $48 \%$. As in any study, a significant number of non-respondents may lead to biased results. A decline in response rates in general is a recognised problem (Owen-Smith, Burgess-Allen, Lavelle, \& Wilding, 2008), and given that the current study comprises a relatively complex sample, and covers questions on health status and sickness absence, it is not surprising that employees hesitated to participate. A strength of the study is the rigorous data collection process. A first survey was followed by a reminder, and after that a second reminder (including a new survey), and then a third (including a shorter and somewhat modified version of the survey).

The use of 'expectations of return to work' as outcome measure for RTW can be questioned. The optimal measure, of course, would be to investigate whether or not the employees actually do return to work, but with the chosen cross-sectional design, this was not possible. However, previous studies (Holmgren et al., 2004; Hou et al., 2012; Lötters \& Burdorf, 2006; Niewenhuijsen et al., 2006, Planan et al., 2012; Shaw \& Huang, 2005) show that the ill or injured worker's own perception of RTW has a strong predictive value regarding actual RTW.

Furthermore, with a cross-sectional design, there is always uncertainty regarding causality. A conclusion of the study is that constructive and supportive contact between the absent employee and his/her supervisor and co-workers contributes to a more positive and optimistic view of RTW. But on the opposite, a positive and optimistic employee may also be more eager to have high-quality contact with his or her workplace. It is also likely that people that had better interactions prior to being off work would have better interactions when they are off work, meaning that people with worse preabsence working relationships will have worse expectations for RTW. Prospective study is needed to address 
the issue of causality. Without such, results must be interpreted with caution.

\section{Conclusions and Practical Implications}

This is the first study of its kind, using a quantitative method to explore the contact between the employee and his/her workplace during a period of long-term sickness absence in Sweden. A further unique factor is that the whole workplace is investigated (i.e., the employees' contacts with all relevant actors at the workplace). The study shows that the majority of employees are satisfied with the contact they have with their supervisor and co-workers. The study also shows that contact quality is important. Employees experiencing supportive and constructive contact are more positive and optimistic about returning to work in the future.

Some practical implications of the study are:

- Supervisors and co-workers should be aware that they play a significant role in the RTW process.

- Supervisors and co-workers should not hesitate to contact a co-worker on long-term sickness benefit. There is no risk for contact being too intense.

- Stay in contact also with the 'quiet ones', not just those that contact you.

- Act in a supportive and constructive way. Quality of contact is more important than quantity. An initial contact by the supervisor is often experienced as supportive and constructive.

- OHS could be more active in their contact with employees.

- Employers could demand more activity from OHS.

Despite the increased interest in the social context of RTW during recent years, it is obvious that much remains to be investigated. Further research is needed, especially with a focus on social aspects of the workplace.

\section{Acknowledgements}

The authors thank Nadine Karlsson, Department of Medical and Health Sciences, Linkoping University, Sweden, for statistical assistance.

The study is funded by AFA Insurance. The authors report no conflict of interest.

\section{References}

Baril, R., Clarke, J., Friesen, M., Stock, S., \& Cole, D. (2003). Management of return-to-work programs for workers with musculoskeletal disorders: A qualitative study in three Canadian provinces. Social Science and Medicine, 57(11), 2101-2014.

Brouwer, S., Reneman, M., Bultmann, U., van der Klink, J., \& Grotthoff, J. (2010). A prospective study of return to work across health conditions: Perceived work attitude, self efficacy and perceived social support. Journal of Occupational Rehabilitation 20, 104-112.
Campbell, P., Wynne-Jones, G., Muller, S., \& Dunn, K.M. (2013). The influence of employment social support for risk and prognosis in nonspecific back pain: a systematic review and critical synthesis. International Archives of Occupational and Environmental Health Feb 86(2), 119-137.

Clay, FJ., Fitzharris, M., Kerr, E., McClure, R.J., \& Watson, W.L. (2012). The association of social functioning, social relationships and the receipt of compensation with time to return to work following unintentional injuries to Victorian workers. Journal of Occupational Rehabilitation, 22(3), 363-375.

Dunstan, D.A., \& MacEachen, E.A. (2013a). Theoretical model of co-worker responses to work reintegration processes. Journal of Occupational Rehabilitation. doi 10.1007/s10926-013-9461-x

Dunstan, D.A., \& MacEachen, E. (2013b). Bearing the brunt: Coworkers experiences of work reintegration process. Journal of Occupational Rehabilitation, 23(1), 44-54.

Ekman, M., Jonhagen, S., Hunsche, E., \& Jonsson, L. (2005). Burden of illness of chronic low back pain in Sweden: a cross sectional, retrospective study in primary care setting. Spine, 30(15), 17771785.

EuroQol Group (1990). EuroQol - a new facility for the measurement of health related quality of life. Health Policy, 16, 199-208.

Flach, P.A., Groothoff, J.W., Bultman, U. (2013). Identifying employees at risk for job loss during sick leave. Disability and Rehabilitation 35(21), 1835-1841.

Franche, R.L., Cullen, K., Clarke, J., Irvin, E., Sinclair, S., Frank, J. (2005). Workplace-based return-to-work interventions: A systematic review of the quantitative literature. Journal of Occupational Rehabilitation, 15(4), 607.

Glozier, N., Hough, C., Henderson, M., \& Holland-Elliott, K. (2006). Attitudes of Nursing Staff Toward Co-Workers Returning from Psychiatric and Physical Illnesses. International Journal of Psychiatry 52, 525-35.

Haugli, L., Maeland, S., \& Magnussen, L.H. (2011). What facilitates return to work? Patients' experiences 3 years after occupational rehabilitation. Journal of Occupational Rehabilitation, 21(4), 573581.

Hepburn, G., Franche, R.L., \& Francis, L. (2010). Successful return to work: The role of fairness and workplace-based strategies. International Journal of Workplace Health Management 3 (1), 7-24.

Holmgren, K., Dahlin, , \& Ivanoff, S. (2004). Women on sickness absence-views of possibilities and obstacles for returning to work. A focus group study. Disability \& Rehabilitation, 26(4), 213-222.

Hou, W.H., Sheu, C.F., Liang, H.W., Hsieh, C.L., Lee, Y. Chuang, H.Y., \& Cheng, Y.T. (2012). Trajectories and predictors of return to work after limb injury - a 2 year follow up study. Scandinavian Journal of Environmental Health, 38(5), 456-466.

Katz, J.N., Amick, B.C., Keller, R., Fossel, A.H., Ossman, J., Soucie, V., \& Losina, E. (2005). Determinants of work absence following surgery for carpal tunnel syndrome. American Journal of Industrial Medicine 47(2), 120-130.

Kong, W., Tang, D., Luo, X., Yu, I.T., Liang, Y., \& He, Y. (2012). Prediction of return to work outcomes under an injured worker case management program. Journal of Occupational Rehabilitation, 22(2), 230-240.

Kosny, A., Lifshen, M., Pugliese, D., Majesky, G., Kramer, D., Steenstra, , ... Carrasco, C. (2013). Buddies in bad times? The role of co-workers after a work-related injury. Journal of Occupational Rehabilitation, 23(3), 438-449.

Lemieux, P., Durand, M.J., \& Hong, Q.N. (2011). Supervisors' perception of the factors influencing the return to work of workers with common mental disorders. Journal of Occupational Rehabilitation, 21, 293-303. 
Lysaght, R.M., \& Larmour-Trode, S. (2008). An exploration of social support as a factor in the return-to-work process. Work 30(3), 255-66.

Lysaght, R., Fabrigar, L., Larmour-Trode, S., Stewart, J., \& Friesen, M. (2012). Measuring Workplace Social Support for Workers with Disability. Journal of Occupational Rehabilitation 22;376-379.

Lötters, F., \& Burdorf, A. (2006). Prognostic factors for duration of sickness absence due to musculoskeletal disorders. Clinical Journal of Pain Feb;22(2), 212-21.

MacEachen, E., Clarke, J., Franche, R.L., Irvin, E.(2006). Systematic review of the qualitative literature on return to work after injury. Scandinavian Journal of Working Environment and Health Aug;32(4), 257-69.

National Insurance Act (Sweden, 1992; trans. Lagen om allmän Försäkring).

National Social Insurance Office. (2011). Social Insurance Report 2011:17. (Sweden; trans. Försäkringskassan. Socialförsäkringsrapport 2011:17).

Nieuwenhuijsen, K., Verbeek, J.H., de Boer, A.G., Blonk, R.W., \& van Dijk, FJ. (2006). Predicting the duration of sickness absence for patients with common mental disorders in occupational care. Scandinavian Journal of Work, Environment and Health, 32(1), 6774 .

Nordqvist, C., Holmqvist, C., \& Alexanderson, K. (2003). Views of laypersons on the role employers play in return to work when sick-listed. Journal of Occupational Rehabilitation, 13(1), 11-20.

Owen-Smith, V., Burgess-Allen, J., Lavelle, K, \& Wilding, E. (2008). Can lifestyle surveys survive a low response rate? Public Health, 122(12), 1382-1383.

Planan, M., Lopez, J.C., Martinez, J.M., Delclos, G.L., \& Benavides, F.G. (2012). Return to work expectations of workers on longterm non-work-related sick-leave. Journal of Occupational Rehabilitation, 22(1), 15-26.

Reynolds, C.A., Wagner, S.L., \& Harder, H.G. (2006). Physicianstakeholder collaboration in disability management: A Canadian perspective on guidelines and expectations. Disability \& Rehabilitation 28(15), 955-63.
Shaw, W.S., Robertson, M.M., Pransky, G., \& McLellan, R.K. (2003). Employee perspectives on the role of supervisors to prevent workplace disability after injuries. Journal of Occupational Rehabilitation, 13(3), 129-142.

Shaw, W.S., \& Huang, Y.H. (2005). Concerns and expectations about returning to work with low back pain: Identifying themes from focus groups and semi-structured interviews. Disability \& Rehabilitation, (27)21, 1269-1281.

Shrey, D.E., \& Hursh, N.C. (1999). Workplace disability management: International trends and perspectives. Journal of Occupational Rehabilitation, 9(1), 45-59.

Svensk Företagshälsovård. (2015). Available from http://www. foretagshalsor.se/foretagshalsovard

Tjulin, A. (2010). Workplace social relations in the return-to-work process (Medical dissertation No. 1197, Likoping University, Sweden).

Tjulin, Å., MacEachen, E., Ekberg, K. (2010). Exploring Workplace Actors Experiences of the Social Organization of Return-to-Work. Journal of Occupational Rehabilitation, 20(3), 311-21.

Tjulin, A., MacEachen, E., Ekberg, K. (2011). Exploring the meaning of early contact in return-to-work from workplace actors perspective. Disability \& Rehabilitation 33(2), 137-145.

Tuomi, K., Ilmarinen, J., Jahkola, A., Katajarinne, L., \& Tulkki, A (1998). Work Ability Index (2nd ed., rev., p. 19) Finnish Institute of Occupational Health, Helsinki, Finland: Occupational Health Care.

Waddell, G., \& Burton, A.K. (2006). Is work good for your health and well-being? London, England: TSO.

Work Environment Act (Sweden, 1977; trans. Arbetsmiljölagen).

Young, A.E (2010). Employment maintenance and the factors that impact it after vocational rehabilitation and return to work. Disability \& Rehabilitation, 32(20), 1621-1632.

Young, A.E., Roessler, R.T., Wasiak, R., McPherson, K.M., van Poppel, M.N., Anema, J.R. (2005). A developmental conceptualization of return to work. Journal of Occupational Rehabilitation, 15(4), 557-568. 